\title{
Inhibitory effect of Lycium barbarum polysaccharides on cell apoptosis and senescence is potentially mediated by the $\mathbf{p 5 3}$ signaling pathway
}

\author{
GUANGQING XIA ${ }^{1}$, NIAN XIN ${ }^{2}$, WEI LIU $^{1}, \mathrm{HUIMIN} \mathrm{YAO}^{1}, \mathrm{YI} \mathrm{HOU}^{2}$ and $\mathrm{JIE} \mathrm{QI}^{2}$ \\ ${ }^{1}$ College of Life Science, Tonghua Normal University, Tonghua, Jilin 134002; \\ ${ }^{2}$ Key Laboratory of Marine Genetics and Breeding, Ocean University of China, Qingdao 266003, P.R. China
}

Received September 17, 2013; Accepted February 3, 2014

DOI: $10.3892 / \mathrm{mmr} .2014 .1964$

\begin{abstract}
Lycium barbarum (L. barbarum) fruit or extract has been regarded as a superior-grade Chinese medicine, used to modulate body immunity and for anti-aging purposes. However, the underlying molecular mechanisms behind these effects remain unclear. In the present study, L. barbarum polysaccharides (LBPs), considered a major contributor of $L$. barbarum effects, were used to elucidate its mechanism of action by phenotypic and senescence associated$\beta$-galactosidase (SA- $\beta$-gal) assays, evaluation of survival rates in vivo and expression profiling of genes related to the p53 signaling pathway in a zebrafish model. Zebrafish embryos were continuously exposed to various concentrations of LBPs $(1.0,2.0,3.0$ and $4.0 \mathrm{mg} / \mathrm{ml})$ for 3 days. The results of fluorescent acridine orange and SA- $\beta$-gal staining indicated that cell apoptosis and senescence mainly occur in the head at 24 hours post fertilization (hpf) and $72 \mathrm{hpf}$. In addition, resistance to replicative senescence was observed at low doses of LBPs, especially at the $3.0 \mathrm{mg} / \mathrm{ml}$ concentration. Furthermore, the expression of genes that relate to aging, such as $p 53, p 21$ and $B a x$, was decreased, while that of $M d m 2$ and TERT genes was increased after treatment with LBPs. The results demonstrated that the effects of LBPs on cell apoptosis and aging might be mediated by the p53-mediated pathway.
\end{abstract}

\section{Introduction}

Aging is defined as the accumulation of diverse deleterious changes in cells and tissues (1). It is commonly associated with a reduction in physiological functions, and is closely related to

Correspondence to: Dr Jie Qi, Key Laboratory of Marine Genetics and Breeding, Ocean University of China, 5 Yushan Road, Qingdao 266003, P.R. China

E-mail: qijie@ouc.edu.cn

Key words: cell apoptosis, Lycium barbarum polysaccharides, senescence, zebrafish apoptosis. In biology, the state or process of aging is known as senescence. It occurs at the level of the organism (organismal senescence), as well as at the level of individual cells (cellular senescence). At the individual cell level there are two types of senescence, replicative and stress-induced premature senescence (SIPS). Genetic and environmental manipulations have revealed that aging is regulated by specific pathways, involved in hormonal signaling, nutrient sensing and signaling, mitochondria and ROS signaling and genome surveillance (2). However, the question of whether all these signaling pathways exert their effects separately, or involve one or more junction co-regulators among these signaling pathways in the aging process remains to be determined.

Chinese herbs have been widely applied in the field of medicine as anti-aging drugs because of their few side-effects $(3,4)$. The plant species Lycium barbarum (L. barbarum) belongs to the family of Solanaceae, and its fruit or extract has been regarded in Chinese pharmacopoeia as a superior-grade medicine for the modulation of body immunity (5-7). The effects of $L$. barbarum are attributed to the polysaccharides (LBPs) it contains, which can upregulate both innate and adaptive immune responses $(8,9)$. It has been shown that LBPs can protect neurons from $\beta$-amyloid peptide neurotoxicity $(10,11)$, and from neuronal death, glial activation and oxidative stress in a murine retinal ischemia/ reperfusion model $(12,13)$.

The tumor suppressor gene $p 53$ has been known to play an important role in the induction of cell cycle arrest and apoptosis (14). In a recent study, LBPs were found to stimulate the proliferation of MCF-7 cells via the ERK pathway, which may be associated with the p53 pathway (15). Although findings of previous studies have demonstrated the beneficial effects of LBPs on the health of humans and animals $(16,17)$, to the best of our knowledge, there have been scarce studies that systematically investigate the signaling pathway(s) via which LBPs exert these beneficial effects, especially in zebrafish, an excellent model for studying angiogenesis, senescence, and toxicity responses (18-21). In this study, we examined senescence during the early development stages of zebrafish, cell apoptosis, and senescence-associated gene expression upon treatment with LBPs from the Chinese herb L. barbarum in the zebrafish model, in order to investigate the effects of this 
A

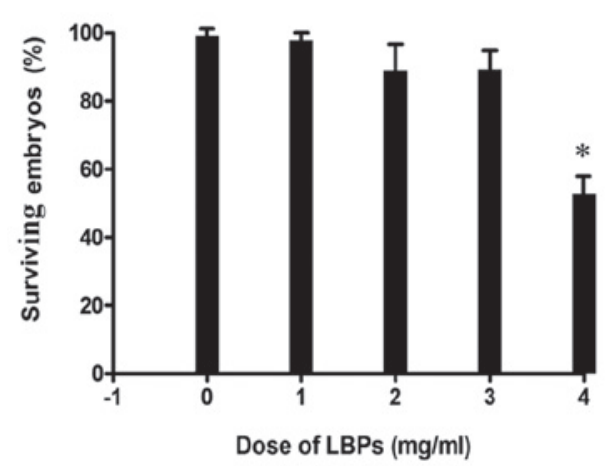

B

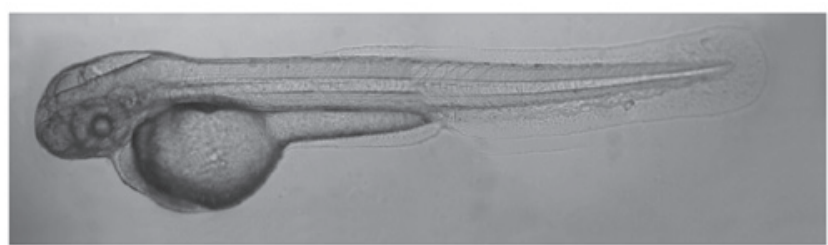

C

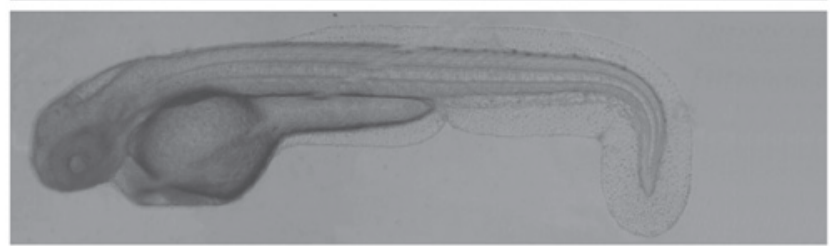

Figure 1. Effect of Lycium barbarum polysaccharides (LBPs) on the growth and development of zebrafish embryos at 48 hours post-fertilization (hpf). (A) The percentage of surviving embryos after treatment with different doses of LBPs. Data are presented as mean \pm SD (n=30). (B) Phenotype of 48 hpf embryos not treated with LBPs and (C) treated with $4 \mathrm{mg} / \mathrm{ml}$ LBPs.

herb and identify the related signaling pathway(s) potentially involved in anti-aging processes.

\section{Materials and methods}

Materials and animals. Purified L . barbarum polysaccharides (LBPs) were purchased from Shanxi Undersun Biomedtech Co., Ltd. (Xi'an, Shaanxi, China) and an extract was prepared using the method of Luo et al (22). Zebrafish were maintained in standard fish facility conditions with a $14: 10 \mathrm{~h}$ light/dark cycle and fed with living brine shrimp twice per day. The water temperature was maintained at $28^{\circ} \mathrm{C}$. The study was approved by the ethics committee of Ocean University of China (Qingdao, China).

Embryo treatment and image collection. Embryos at 8 hours post-fertilization (hpf) were placed into a 24-well microplate (Millipore Co., Bedford, MA, USA). Thirty embryos were continuously exposed to varying concentrations of LBPs $(0,1,2,3$ and $4 \mathrm{mg} / \mathrm{ml})$ for 3 days (d). LBPs were renewed daily. Each treatment with an LBP concentration was repeated three times and the standard deviation was calculated. To collect images of embryo phenotypes, treated and non-treated embryos were anesthetized with $0.2 \mathrm{mg} / \mathrm{ml}$ tricaine (3-aminobenzoic acid ethylester; Sigma-Aldrich, St. Louis, MO, USA) and embedded in methylcellulose.

Senescence associated- $\beta$-galactosidase (SA- $\beta$-gal) assay. Embryos of $72 \mathrm{hpf}$ were fixed in $4 \%$ paraformaldehyde in phosphate-buffered saline, at $4^{\circ} \mathrm{C}$ overnight. Staining of SA- $\beta$-gal and quantifications were performed according to the method of Kishi et al (23).

In vivo detection of cell death. For the in vivo detection of cell death, 2 day-old embryos were incubated in $5 \mathrm{mg} / \mathrm{ml}$ acridine orange stain (AO; Sigma-Aldrich) in zebrafish embryo medium [NaCl, $5.03 \mathrm{mM}$; KCl, $0.17 \mathrm{mM} ; \mathrm{CaCl}_{2} \cdot 2 \mathrm{H}_{2} \mathrm{O}, 0.03 \mathrm{mM}$; $\mathrm{MgSO}_{4} \cdot 7 \mathrm{H}_{2} \mathrm{O}, 0.03 \mathrm{mM}$; methylene blue, $\left.0.1 \%(\mathrm{w} / \mathrm{v})\right]$ and kept in the dark for $15-30 \mathrm{~min}$ at $28^{\circ} \mathrm{C}$, then rinsed thoroughly 8 times with egg water. Stained embryos were anesthetized with MESAB (0.5 mM 3-aminobenzoic acid ethyl ester, $2 \mathrm{mM}$ $\mathrm{Na}_{2} \mathrm{HPO}_{4}$ ) and mounted in a depression slide for observation using methylcellulose. They were then visualized using a fluorescence microscope (AZ100, Nikon, Tokyo, Japan) and images were captured for $<60 \mathrm{sec}$ (the signal is quenched after $60 \mathrm{sec}$ of exposure to fluorescence). Embryos that were not stained with $\mathrm{AO}$ were used to determine baseline fluorescence.

Semi-quantitative RT-PCR. Total RNA was extracted from 72 hpf embryos using the TRIzol reagent. Semi-quantitative PCR was performed with an initial incubation for $5 \mathrm{~min}$ at $94^{\circ} \mathrm{C}$, followed by 22 cycles of incubation at $94^{\circ} \mathrm{C}$ for $30 \mathrm{sec}$, $55^{\circ} \mathrm{C}$ for $30 \mathrm{sec}$, and $72^{\circ} \mathrm{C}$ for $30 \mathrm{sec}$. The primers for amplification of $p 53$ and $p 21$ were the same as in (24): p53 forward/ reverse: CTCTCCCACCAACATCCACT/ACGTCCACC ACCATTTGAAC; p21 forward/reverse: CGGAATAAA CGGTGTCGTCT/CGCAAACAGACCAACATCAC. The primers for amplification of Bax, Mdm2, TERT and $\beta$-actin were: $B a x$ forward/reverse: GGAGATGAGCTGGAT GGAAAT/ATGACGTGCTCCTGAATGTAG; $M d m 2$ forward/reverse: GACTACTGGAAGTGTCCCAAAT/ GTCCACTCCATCATCTGTTTCT; TERT forward/reverse: GTGTGTGTGTCCTGGGTAAA/CAGCCTGAGGTCTAA

GAAGATG; $\beta$-actin forward/reverse: CCCAGACATCAG GGAGTGAT/TCTCTGTTGGCTTTGGATT. Subsequently, $10 \mu 1$ PCR products were loaded into gels for agarose gel electrophoresis.

Statistical analysis. Data are presented as mean \pm SD $(n=30)$. Differences between groups were assessed by analysis of variance (ANOVA) and Student's t-tests. Statistical analyses was carried out using SPSS for Windows, Version 11.5 (SPSS Inc., Chicago, IL, USA).

\section{Results}

Zebrafish embryo bioassay for assessing the toxicity of LBPs. The dose of LBPs that was lethal for embryos was determined by incubating embryos in different concentrations of LBPs. The results indicated that the growth and development of embryos were significantly inhibited at the concentration of $4.0 \mathrm{mg} / \mathrm{ml}$ (Fig. 1A). The number of surviving embryos was not significantly different among the lower concentrations $(0,1,2$ and $3 \mathrm{mg} / \mathrm{ml}$ ). Half of the embryos died in this experiment, and 

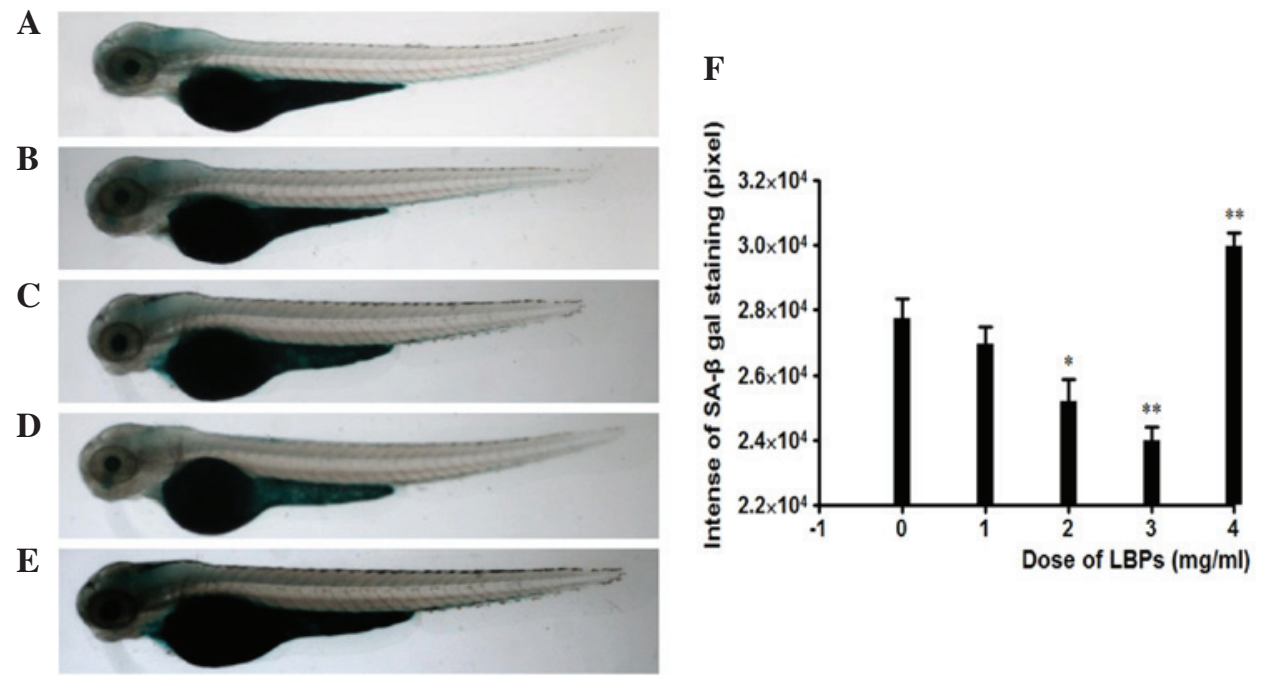

Figure 2. Senescence associated- $\beta$-galactosidase (SA- $\beta$-gal) activity changes in 72-hour post fertilization (hpf) embryos treated with Lycium barbarum polysaccharides (LBPs). Phenotype of (A) non-treated and (B-E) treated embryos with 1,2,3 and $4 \mathrm{mg} / \mathrm{ml}$ of LBPs, respectively. (F) Relative intensities of SA- $\beta$-gal staining expressed as pixels from computer scanning analysis. ${ }^{* *} \mathrm{P}<0.05 \mathrm{vs}$. $(0 \mathrm{mg} / \mathrm{ml}) ;{ }^{* * *} \mathrm{P}<0.01 \mathrm{vs}$. control $(0 \mathrm{mg} / \mathrm{ml})$.
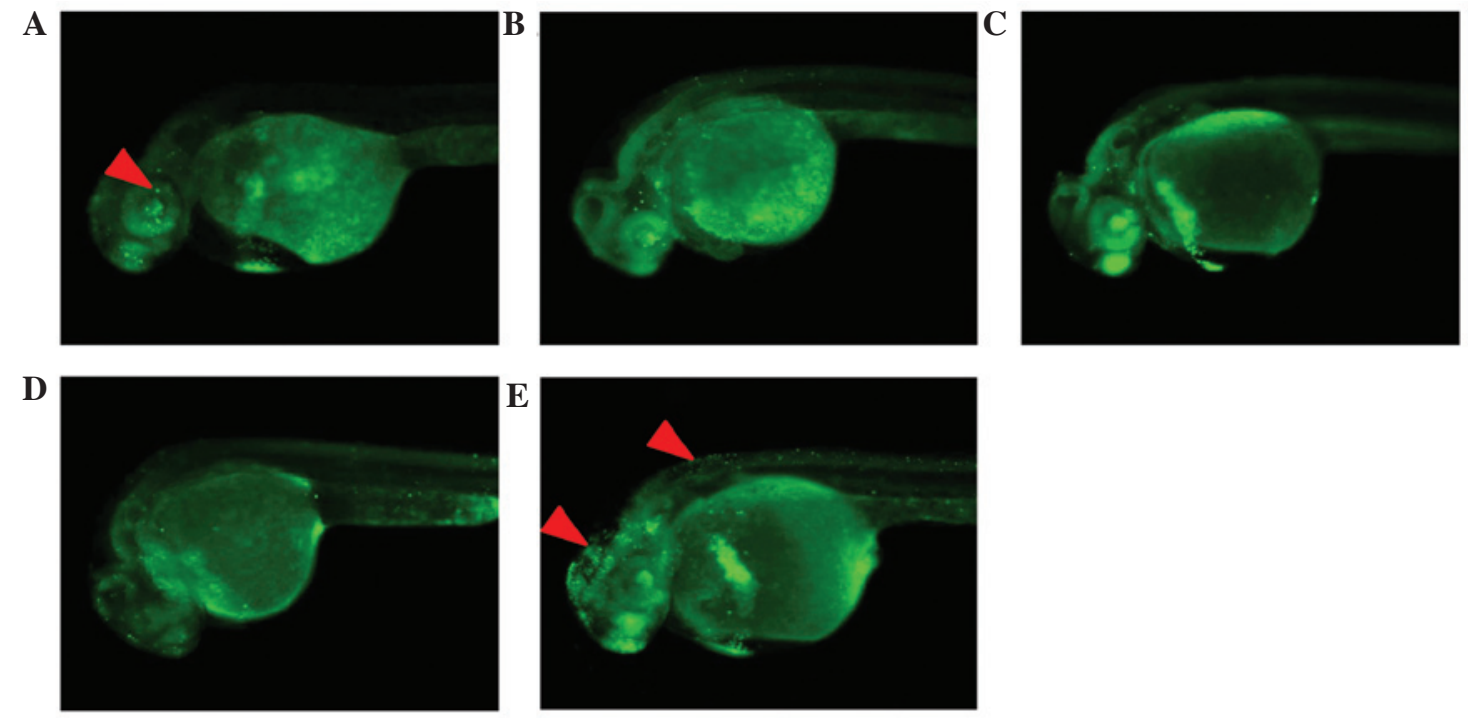

Figure 3. Representative cellular death phenotypes detected at 24 hours post-fertilization (hpf). (A-E) Microscopic images of acridine orange (AO) staining on embryos treated with $0,1,2,3$ and $4 \mathrm{mg} / \mathrm{ml}$ of Lycium barbarum polysaccharides (LBPs), respectively. Quantitative analysis revealed that apoptosis decreased in a dose-dependent manner and that the $4 \mathrm{mg} / \mathrm{ml}$ concentration of LBPs induced cell apoptosis. Red arrowheads denote the main areas of positive staining.

the embryos showed an abnormal phenotype (Fig. 1B and C) when treated with the highest concentration of LBPs tested in the present study $(4 \mathrm{mg} / \mathrm{ml})$.

\section{Assessing senescence in zebrafish embryos}

$S A-\beta$-gal staining. Cytochemically and histochemically detectable SA- $\beta$-gal at $\mathrm{pH} 6.0$ has been shown to increase during the replicative senescence of cells in vitro and in tissue samples (25), and has subsequently been widely used as an in vivo and in vitro marker of cellular senescence in a number of vertebrate animal systems (26-28). To assess the effect of LBPs on replicative senescence, the SA- $\beta$-gal activity was histochemically detected at $\mathrm{pH} 6.0$ in the $72 \mathrm{hpf}$ embryos. The untreated embryos exhibited low background staining, especially in the head (Fig. 2A), while embryos treated with LBPs showed faint background staining, which was reduced with

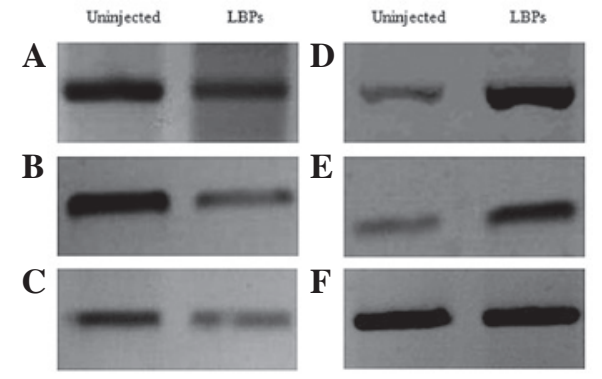

Figure 4. Expression profiles of key genes related to senescence at 72 hours post fertilization (hpf) in zebrafish treated with $3 \mathrm{mg} / \mathrm{ml}$ Lycium barbarum polysaccharides (LBPs) and in non-treated animals (uninjected). (A-C) The expression levels of genes encoding the regulatory protein $\mathrm{p} 53$, the cell cycle checkpoint protein $\mathrm{p} 21$ and the apoptotic- and senescence-related protein Bax respectively, increased upon treatment with LBPs, while those of genes encoding the (D-E) p53 regulator Mdm2 and the apoptotic- and senescence-related protein TERT decreased. (F) $\beta$-actin was used as a control of baseline expression. 
treatment with increased concentrations of LBPs (Fig. 2B-D). Only at the $4 \mathrm{mg} / \mathrm{ml}$ concentration were embryos more strongly stained compared to untreated ones and to those treated with 1-3 mg/ml LBPs (Fig. 2E). Quantification of SA- $\beta$-gal staining was performed using high-resolution digital imagery. SA- $\beta$-gal staining at 1,2 and $3 \mathrm{mg} / \mathrm{ml}$ LBPs was estimated to correspond to $88.3,81.7$ and $68.3 \%$ of the staining observed in the control (treated with $0 \mathrm{mg} / \mathrm{ml} \mathrm{LBPs}$ ), while it was $112.7 \%$ of the control for the $4 \mathrm{mg} / \mathrm{ml}$ LBPs ,as shown in Fig. 2F. The less amount of staining was equivalent to that of the less senescent mass.

Acridine orange (AO) staining. To explore the effect of LBPs on apoptosis, AO staining was performed. Treatment with 1-3 mg/ml LBPs reduced cell apoptosis in a dose-dependent manner (Fig. 3A-D), while at the $4 \mathrm{mg} / \mathrm{ml}$ LBPs concentration, cell apoptosis was induced, as observed from the comparison to control animals and to those treated with lower LBPs concentrations (Fig. 3E). Embryos treated with $4 \mathrm{mg} / \mathrm{ml}$ LBPs showed high levels of AO staining (red arrowheads) in the brain and the neural tube, compared to non-treated embryos (Fig. 3A) at $24 \mathrm{hpf}$.

The expression levels of genes related to the p53 signaling pathway after LBPs treatment. It was reported that in MCF-7 breast cancer cells, LBPs can activate ERK, which may be associated with the p53 signaling pathway (15). There is also the hypothesis that different types of intrinsic and extrinsic stress signals likely converge on the activation of the p53 protein, the Rb protein, or both during senescence (29). In this context, we examined whether zebrafish and mammals share similar mechanisms for the response to LBPs treatment. To further investigate p53-dependent transcriptional responses in the treated embryos, we examined the expression of $p 53$, along with that of response genes such as $p 21, M d m 2$ and $B a x$, using semi-quantitative RT-PCR and the $\beta$-actin gene as a control of baseline expression. The results showed that the expression level of $p 53, p 21$ and Bax were decreased in treated embryos compared to non-treated ones (Fig. 4A-C), while the levels of $M d m 2$ and even, that of the cellular senescence-related (30-32) telomerase reverse transcriptase (TERT), which allows to maintain the telomere ends, were increased (Fig. 4D and E).

\section{Discussion}

L. barbarum fruits (berries) or extract have been widely used for centuries to balance the 'Yin' and the 'Yang' in the body (33). The major ingredient of the liquid fraction of these berries, LBPs, has been the object of research focus in studies aiming to identify anti-aging remedies (34) or agents alleviating cellular damage $(12,35)$.

p53, as a central mediator of cellular responses induced in various processes including apoptosis (36), was shown to exert similar effects to ERK during stress induced by DNA damage (37). In MCF-7 cells, LBPs increased the activity of ERK (15). p21 as a regulator of cell cycle progression controlled by the tumor suppressor protein $\mathrm{p} 53$, inhibited tumor progression, thus preventing cell proliferation, while inducing cell apoptosis (38). In our study, cell apoptosis was inhibited following treatment with non-toxic doses of LBPs (1-3 $\mathrm{mg} / \mathrm{ml})$, as shown by AO staining, the reduced expression of $p 53$ and the increased expression of its negative regulator, $M d m 2$. A potential explanation for these findings is that the cellular responses triggered by the activated p53 protein (cellular senescence) act as potent barriers against the effects of LBPs.

In this study, we assessed the relevance of one molecular mechanism potentially underlying the effect of LBPs on cellular senescence in a zebrafish model by phenotypic and SA- $\beta$-gal assays, in vivo detection of survival rates and expression profiling of genes that related to the p53 signaling pathway during senescence. Zebrafish senescence was alleviated by LBPs via inhibition of cell death and apoptosis in the early development, a reduction in the expression level of $p 53$, p21 and Bax genes and an increase in the expression of $M d m 2$ and TERT genes. In conclusion, our findings suggest that the anti-aging effects of LBPs are mediated by the p53 signal pathway. The specific targets of LBPs in this pathway may be identified in future studies.

\section{Acknowledgements}

This study was financially supported by a grant from the Jilin Provincial Science \& Technology Department (no. 201215227).

\section{References}

1. Harman D: The free radical theory of aging. Antioxid Redox Signal 5: 557-561, 2003.

2. Greer EL and Brunet A: Signaling networks in aging. J Cell Sci 121: 407-412, 2008.

3. Bastianetto $\mathrm{S}$ and Quirion R: Natural extracts as possible protective agents of brain aging. Neurobiol Aging 23: 891-897, 2002.

4. Chang IM: Anti-aging and health-promoting constituents derived from traditional oriental herbal remedies: information retrieval using the TradiMed 2000 DB. Ann NY Acad Sci 928: 281-286, 2001.

5. Gan L, Zhang SH, Liu Q and Xu HB: A polysaccharide-protein complex from Lycium barbarum upregulates cytokine expression in human peripheral blood mononuclear cells. Eur J Pharmacol 471: 217-222, 2003.

6. Li XM, Ma YL and Liu XJ: Effect of the Lycium barbarum polysaccharides on age-related oxidative stress in aged mice. J Ethnopharmacol 111: 504-511, 2007.

7. Zhang M, Chen H, Huang J, Li Z, Zhu C and Zhang S: Effect of lycium barbarum polysaccharide on human hepatoma QGY7703 cells: inhibition of proliferation and induction of apoptosis. Life Sci 76: 2115-2124, 2005.

8. Du G, Liu L and Fang J: Experimental study on the enhancement of murine splenic lymphocyte proliferation by Lycium barbarum glycopeptide. J Huazhong Univ Sci Technolog Med Sci 24: 518-520, 527, 2004.

9. Vidal K, Benyacoub J, Sanchez-Garcia J, et al: Intake of a milkbased wolfberry formulation enhances the immune response of young-adult and aged mice. Rejuvenation Res 13: 47-53, 2010.

10. Yu MS, Lai CS, Ho YS, et al: Characterization of the effects of anti-aging medicine Fructus lycii on beta-amyloid peptide neurotoxicity. Int J Mol Med 20: 261-268, 2007.

11. Yu MS, Leung SK, Lai SW, et al: Neuroprotective effects of antiaging oriental medicine Lycium barbarum against beta-amyloid peptide neurotoxicity. Exp Gerontol 40: 716-727, 2005.

12. Li SY, Yang D, Yeung CM, et al: Lycium barbarum polysaccharides reduce neuronal damage, blood-retinal barrier disruption and oxidative stress in retinal ischemia/reperfusion injury. PLoS One 6: e16380, 2011.

13. Jin M, Huang Q, Zhao K and Shang P: Biological activities and potential health benefit effects of polysaccharides isolated from Lycium barbarum L. Int J Biol Macromol 54: 16-23, 2013.

14. May P and May E: Twenty years of p53 research: structural and functional aspects of the p53 protein. Oncogene 18: 7621-7636, 1999.

15. Shen L and Du G: Lycium barbarum polysaccharide stimulates proliferation of MCF-7 cells by the ERK pathway. Life Sci 91: 353-357, 2012. 
16. Keller ET and Murtha JM: The use of mature zebrafish (Danio rerio) as a model for human aging and disease. Comp Biochem Physiol C Toxicol Pharmacol 138: 335-341, 2004.

17. Tsai SB, Tucci V, Uchiyama J, et al: Differential effects of genotoxic stress on both concurrent body growth and gradual senescence in the adult zebrafish. Aging Cell 6: 209-224, 2007.

18. Parng C, Seng WL, Semino C and McGrath P: Zebrafish: a preclinical model for drug screening. Assay Drug Dev Technol 1 : 41-48, 2002.

19. Gerhard GS, Kauffman EJ, Wang X, et al: Life spans and senescent phenotypes in two strains of zebrafish (Danio rerio). Exp Gerontol 37: 1055-1068, 2002.

20. Herrera M and Jagadeeswaran P: Annual fish as a genetic model for aging. J Gerontol A Biol Sci Med Sci 59: 101-107, 2004.

21. Granato $M$ and Nusslein-Volhard C: Fishing for genes controlling development. Curr Opin Genet Dev 6: 461-468, 1996.

22. Luo Q, Cai Y, Yan J, Sun M and Corke H: Hypoglycemic and hypolipidemic effects and antioxidant activity of fruit extracts from Lycium barbarum. Life Sci 76: 137-149, 2004.

23. Kishi S, Bayliss PE, Uchiyama J, et al: The identification of zebrafish mutants showing alterations in senescence-associated biomarkers. PLoS Genet 4: e1000152, 2008.

24. Robu ME, Larson JD, Nasevicius A, et al: p53 activation by knockdown technologies. PLoS Genet 3: e78, 2007.

25. Dimri GP, Lee X, Basile G, et al: A biomarker that identifies senescent human cells in culture and in aging skin in vivo. Proc Natl Acad Sci USA 92: 9363-9367, 1995.

26. Cao L, Li W, Kim S, Brodie SG and Deng CX: Senescence, aging, and malignant transformation mediated by $\mathrm{p} 53$ in mice lacking the Brcal full-length isoform. Genes Dev 17: 201-213, 2003.

27. Keyes WM, Wu Y, Vogel H, Guo X, Lowe SW and Mills AA p63 deficiency activates a program of cellular senescence and leads to accelerated aging. Genes Dev 19: 1986-1999, 2005.

28. Ikegami R, Zhang J, Rivera-Bennetts AK and Yager TD: Activation of the metaphase checkpoint and an apoptosis programme in the early zebrafish embryo, by treatment with the spindle-destabilising agent nocodazole. Zygote 5: 329-350, 1997
29. Ben-Porath I and Weinberg RA: When cells get stressed: an integrative view of cellular senescence. J Clin Invest 113: 8-13, 2004.

30. Concetti F, Lucarini N, Carpi FM, et al: The functional VNTR MNS16A of the TERT gene is associated with human longevity in a population of Central Italy. Exp Gerontol 48: 587-592, 2013.

31. Jaskelioff M, Muller FL, Paik JH, et al: Telomerase reactivation reverses tissue degeneration in aged telomerase-deficient mice. Nature 469: 102-106, 2011.

32. Wyllie FS, Jones CJ, Skinner JW, et al: Telomerase prevents the accelerated cell ageing of Werner syndrome fibroblasts. Nat Genet 24: 16-17, 2000.

33. Chang RC and So KF: Use of anti-aging herbal medicine, Lycium barbarum, against aging-associated diseases. What do we know so far? Cell Mol Neurobiol 28: 643-652, 2008.

34. Potterat O: Goji (Lycium barbarum and L. chinense): Phytochemistry, pharmacology and safety in the perspective of traditional uses and recent popularity. Planta Med 76: 7-19, 2010.

35. Yang D, Li SY, Yeung CM, et al: Lycium barbarum extracts protect the brain from blood-brain barrier disruption and cerebral edema in experimental stroke. PLoS One 7: e33596, 2012.

36. Koivusalo R, Krausz E, Ruotsalainen P, Helenius $H$ and Hietanen S: Chemoradiation of cervical cancer cells: targeting human papillomavirus E6 and p53 leads to either augmented or attenuated apoptosis depending on the platinum carrier ligand. Cancer Res 62: 7364-7371, 2002

37. Singh S, Upadhyay AK, Ajay AK and Bhat MK: p53 regulates ERK activation in carboplatin induced apoptosis in cervical carcinoma: a novel target of p53 in apoptosis. FEBS Lett 581: 289-295, 2007.

38. Gomez-Manzano C, Fueyo J, Kyritsis AP, et al: Characterization of p53 and p21 functional interactions in glioma cells en route to apoptosis. J Natl Cancer Inst 89: 1036-1044, 1997. 